\title{
Avaliação da Microestrutura e Propriedades Mecânicas de Metais de Solda Obtidos por Processos de Soldagem Manual e Automatizado utilizado na Soldagem de Aço API 5L X80.
}

\author{
(Evaluation of Microstructure and Mechanical Properties of weld metals obtained by Manual and Automated Welding Process \\ used in the Welding of API 5L X80 Steel)
}

\author{
Siderley Fernandes Albuquerque ${ }^{1}$, Theophilo Moura Maciel ${ }^{1}$, Marco Antônio dos Santos ${ }^{1}$, Alexandre Queiroz Bracarense ${ }^{2}$ \\ ${ }^{1}$ Universidade Federal de Campina Grande-UFCG, DEM, LABSOL, Campina Grande, Paraíba, Brasil \\ ${ }^{2}$ Universidade Federal de Minas Gerais-UFMG, DEM, LRSS, Minas Gerais, Belo Horizonte, Brasil \\ siderleyfernandes@yahoo.com
}

\begin{abstract}
Resumo
O objetivo do trabalho foi avaliar as características da zona termicamente afetada (ZTA) e a microestrutura e propriedades mecânicas de metais de solda de juntas soldadas do aço API 5L X80, obtidos para quatro diferentes procedimentos de soldagem utilizando processos manuais e automatizados. Para isto, chapas do referido aço foram soldadas por processo manual ao Arco Elétrico com Eletrodo Revestido (SMAW), utilizando 473 e 673 K como temperaturas de interpasses e o eletrodo celulósico AWS E8010-G como consumivel; por processo ao Arco Elétrico com Arame Tubular (FCAW) robotizado, utilizando o arame AWS E71T-1C como metal de adição e argônio com $25 \% \mathrm{CO}_{2}$ como gás de proteção; por processo a Arco Elétrico com Eletrodo de Tungstênio (GTAW) mecanizado na raiz da solda, usando o arame ER7OS-3 e argônio como gás de proteção. As análises microestruturais foram relacionadas com os resultados de ensaios de impacto Charpy nos metais de solda e com os perfis de microdureza Vickers ao longo da junta soldada. Os resultados indicaram maiores percentuais de Ferrita Acicular e maiores valores de resistência ao impacto nos metais de solda e uma menor extensão e granulometria da ZTA, associado ao procedimento de soldagem utilizando processo automatizado com maior velocidade de soldagem.
\end{abstract}

Palavras-chave: aço API 5L X80, soldagem automatizada, microestrutura, metal de solda, ZTA, resistência ao impacto, microdureza.

\section{Abstract:}

The objective of this work was to evaluate the heat affected zone characteristics and weld metals microstructure and mechanical properties of API $5 L$ X80 steel welded joints, obtained for four different welding procedures using manual and automated processes. For this, plates of this steel were welded by manual Shielded Metal Arc Welding (SMAW) process with interpasses temperatures of 473 e 673 $K$, and using AWS E8010-G electrode as filler metals; robotized Flux Cored Arc Welding (FCAW) process, using AWS E71T-1C wire and Ar25\% $\mathrm{CO}_{2}$ as consumable and mechanized Gas Tungsten Arc Welding (GTAW) process, for the root pass using AWS ER7OS-3 and Ar as consumable. The microstructural analysis was related with the weld metals Charpy impact test results and with the welded joint Vickers microhardness profiles. The results indicated that weld metals obtained by automatized welding process presented a shorter and more refined heat affected zone and a weld metal with greatest Acicular Ferrite percentiles which promoted the best results of the impact test.

Key-words: API 5L X80 steel, automated welding, microstructure, weld metal, impact resistance, microhardness.

\section{Introdução}

Com a crescente demanda na produção de petróleo e gás e a sua descoberta na camada pré-sal, a utilização de aços como o API 5L X80 na fabricação de tubulações vem ganhando espaço no mercado nacional. Estes aços, que estão entre os chamados de Alta Resistência e Baixa Liga (ARBL), apresentam alta resistência mecânica e boa tenacidade, possibilitando redução do peso da tubulação e, conseqüentemente, redução de custos de fabricação e maior facilidade de transporte e instalação [1].

(Recebido em 08/11/2010; Texto final em 10/11/2011).

Artigo originalmente publicado no CONSOLDA 2010
Fatores como alta resistência mecânica, boa soldabilidade e baixa temperabilidade são requisitos importantes na fabricação de aços para tubulações, principalmente em tubos que conduzem fluidos variados sob pressão, como petróleo e seus derivados [2].

O Instituto Americano de Petróleo (American Petroleum Institute - API) exige que esses aços sejam elaborados com as melhores práticas para a produção de aços limpos, assegurando sua aplicação em atividades onde a tenacidade é um requisito fundamental. Logo, para ser classificado como um aço API, o material tem que preencher requisitos como composição química, tenacidade e controle dimensional [3].

$\mathrm{Na}$ soldagem de um aço como o API 5L X80, existe a necessidade do maior controle dos parâmetros de soldagem e, conseqüentemente, a obtenção de uma junta soldada com perfil homogêneo e com o mínimo de descontinuidades de soldagem, 
possibilitando manter na junta soldada uma microestrutura com boa relação entre resistência e tenacidade, característica principal deste tipo de aço.

Uma granulação grosseira no metal de solda não é necessariamente prejudicial à tenacidade, desde que o microconstituinte presente nesta região da junta soldada seja predominantemente constituído de Ferrita Acicular (AF). Este microconstituinte apresenta granulação fina e entrelaçada, composta por finas ripas de ferrita com cementita entre estas ripas [4]. Devido à distribuição caótica das ripas de ferrita, a presença deste microconstituinte é favorável ao aumento da tenacidade no metal de solda de aços ARBL, possibilitando uma boa relação entre resistência e tenacidade $[5,6]$.

Além do tipo de microconstituinte presente, a morfologia do grão exerce um papel importante na tenacidade do metal de solda. Grãos equiaxiais refinados pelo passe subseqüente proporcionam melhores valores de tenacidade quando comparados com grãos colunares que não foram afetados pelo ciclo térmico de soldagem [7]. É sabido, de um modo geral, que a estrutura de solda é pouco resistente ao choque, porque o metal de solda geralmente consiste de grãos colunares [8].

A extensão da zona termicamente afetada assim com a sua granulometria é também de fundamental importância no que diz respeito às propriedades mecânicas da junta soldada. Nos aços API 5L X80, estes aspectos devem ser considerados com um cuidado redobrado, pois são aços de maior resistência obtidos por processo de laminação controlada. Assim, quanto menor a extensão e a granulometria da ZTA, menor a modificação desta estrutura e menor o seu risco de fragilização devido à formação de microestruturas frágeis e à formação do microconstuinte M-A, sendo composto de uma mistura de martensita e austenita retida que durante o resfriamento não teve tempo para se decompor em ferrita e carbonetos. A formação deste constituinte é influenciada pelos ciclos térmicos de soldagem, principalmente para o caso de soldas multipasse de aços ARBL, e também pela composição química. A sua fração volumétrica tende a aumentar com menores taxas de resfriamento e sua presença tende a deteriorar a tenacidade nesta região da junta soldada, [9,10]. Tanto a microestrutura do metal de solda como as características da ZTA dependem, além da composição química dos consumíveis, dos parâmetros, procedimentos e processos de soldagem utilizados.

Desde a década de 70, a tecnologia da soldagem no Brasil vem experimentando uma troca gradual de processos de soldagem, substituindo a soldagem manual com eletrodo revestido por processos semiautomáticos, ou mesmo com a automação de processos de soldagem [11].

Com o emprego da automatização, tem-se um maior controle nos parâmetros de soldagem, proporcionando uma maior eficiência no processo de soldagem e redução do tempo de soldagem, assim como uma maior repetibilidade na execução da junta soldada. Já na soldagem manual, existe uma grande dependência da habilidade e experiência do soldador, essencial para garantia da qualidade da solda. Contudo, o processo mais utilizado para a soldagem transversal de tubos ainda é o ao Arco Elétrico com Eletrodo Revestido. Por outro lado, o processo ao Arco Elétrico com Arame Tubular, sendo semiautomático e proporcionando a mesma vantagem dos processos com proteção gasosa de garantir uma menor chance de fragilização por hidrogênio, possui a mesma versatilidade para adequação da composição química do revestimento do eletrodo, podendo proporcionar juntas com melhores propriedades mecânicas e maior produtividade [12-16]. Entretanto para a aplicação do passe de raiz é necessário um maior controle principalmente com relação à contaminação por hidrogênio. Assim, a aplicação do processo com proteção de Gás Inerte e Eletrodo de Tungstênio (GTAW) pode ser uma boa alternativa apesar da menor velocidade de soldagem.

Os processos automatizados ou robotizados possibilitam uma soldagem com maior velocidade de deslocamento e, portanto, um menor tamanho e uma maior uniformidade da ZTA, este último aspecto devido à menor variabilidade de suas condições operacionais. Neste contexto, o objetivo deste trabalho foi avaliar a influência dos parâmetros e consumíveis usados em procedimentos de soldagem manual e automatizada sobre a microestrutura, microdureza e resistência ao impacto de metais de solda de juntas soldadas do aço API 5L X80 e sobre a extensão e granulometria da zona termicamente afetada, assim como uma análise qualitativa de sua microestrutura.

\section{Materiais e Métodos}

Os corpos de prova foram extraidos de uma chapa de aço API 5L X80 de 19 mm de espessura. A microestruutra do material foi caracatrerizada como ferrita aloganda e bainita granular com formação de microconstituinte M-A, conforme Figura 1.

Na Tabela 1 é apresentada a composição química do aço obtida por espectroscopia de massa, onde o valor do Pcm é igual a 17.

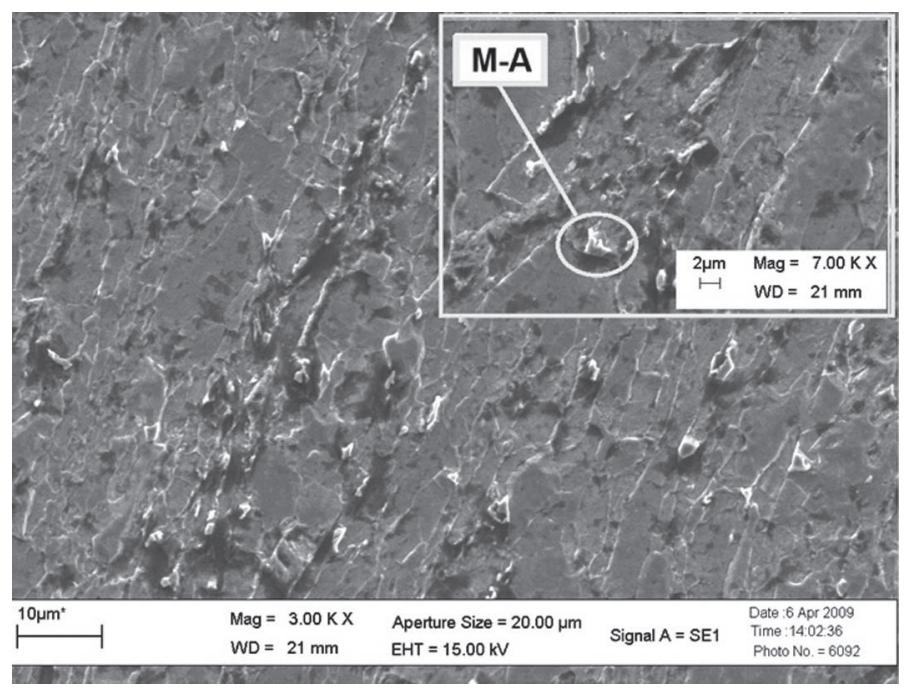

Figura 1. Microestrutura do aço API 5L X80 usado no estudo, 3000x e 7000x. 
Tabela 1. Composição química do aço API 5L X80 (\%massa)

\begin{tabular}{cccccccccccccc}
\hline $\mathbf{C}$ & $\mathbf{M n}$ & $\mathbf{S i}$ & $\mathbf{P}$ & $\mathbf{S}$ & $\mathbf{A l}$ & $\mathbf{N b}$ & $\mathbf{V}$ & $\mathbf{T i}$ & $\mathbf{C r}$ & $\mathbf{M o}$ & $\mathbf{C u}$ & $\mathbf{B}$ & $\mathbf{N i}$ \\
\hline 0,041 & \multirow{2}{*}{1,654} & 0,192 & 0,016 & 0,005 & 0,032 & 0,063 & 0,031 & 0,013 & 0,142 & 0,212 & 0,024 & 0,003 & 0,023 \\
\hline
\end{tabular}

Tabela 2. Parâmetros de soldagem.

\begin{tabular}{|c|c|c|c|}
\hline \multirow{2}{*}{ PS } & \multicolumn{2}{|c|}{ Corrente de Soldagem (A)/ Tensão (V)/ Velocidade de Sodagem (mm/s)/ Aporte Térmico (kJ/mm) } \\
\cline { 2 - 4 } & Passe de Raiz & Passe de enchimento & Passe de acabamento \\
\hline M1 & $100 / 25,5 / 2,0 / 1,25$ & $110 / 26,5 / 2,2 / 1,35$ & $110 / 26,5 / 2,6 / 1,14$ \\
\hline M2 & $90 / 27,5 / 1,3 / 1,87$ & $100 / 27,5 / 1,4 / 1,93$ & $100 / 27,5 / 1,45 / 1,86$ \\
\hline R1 & $120 / 18,0 / 2,5 / 0,86$ & $160 / 22,0 / 3,0 / 1,20$ & $160 / 22,0 / 3,0 / 1,20$ \\
\hline R2 & $190 / 15,5 / 1,3 / 2,10$ & $155 / 21,0 / 4,2 / 0,80$ & $155 / 21,0 / 4,2 / 0,80$ \\
\hline
\end{tabular}

As chapas foram soldadas por processo Manual com Eletrodo Revestido (SMAW), com temperaturas de interpasse de 200 (procedimento M1) e $400{ }^{\circ} \mathrm{C}$ (procedimento M2); com Arame Tubular (FCAW) robotizado (procedimento R1) protegido com argônio com $25 \% \mathrm{CO}_{2}$ e, com Eletrodo de Tungstênio (GTAW) mecanizado na raiz e protegido com argônio mais enchimento FCAW robotizado (procedimento R2). Os consumíveis foram escolhidos de acordo com sugestões encontradas em catálogo de fabricantes para diferentes processos de soldagem do aço API 5L X80. No processo SMAW foi utilizado eletrodo celulósico AWS E8010G com diâmetros de 3,25 mm e 4,0 mm. No processo FCAW utilizou-se o arame E71T-1C com 1,2 mm de diâmetro e no processo GTAW o arame ER70S-3 com diâmetro de 3,0 mm.

Os parâmetros de soldagem utilizados em cada processo, assim como o valor do aporte térmico observado em cada procedimento estão apresentados na Tabela 2.

Para proporcionar um melhor posicionamento do entalhe dos corpos de prova de impacto tanto na ZTA quanto no metal de solda, optou-se por usar chanfros em "K".

Nos procedimentos M1, M2 foram realizados 8 passes alternados, e utilizando uma abertura de chanfro de $30^{\circ}$; no procedimento de soldagem R1 utilizou-se a mesma geometria de chanfro, assim como mesmo número e seqüência de passes que o empregado no procedimento M1, porém, após a soldagem constatou-se que a utilização de uma abertura de chanfro de $30^{\circ}$ ocasionou defeitos de soldagem que impossibilitaram a retirada de corpos de prova para testes de impacto Charpy na região de enchimento, logo, optou-se por modificar esta abertura de chanfro no procedimento $\mathrm{R} 2$ para $60^{\circ}$, facilitando a soldagem robotizada com arame tubular; entretanto, foi necessário um maior numero de passes, total de $8 \mathrm{em}$ cada face, sendo realizados de forma alternada,

A análise macroscópica foi feita por meio visual e também com o auxilio de câmera digital e scaner, visando observar possíveis defeitos de soldagem bem como a morfologia da seção transversal do cordão de solda, possibilitando realizar a quantificação de grãos colunares e equiaxiais.

A análise microscópica foi realizada por um microscópio óptico OLYMPUS BX 51M, interligado a um computador contendo o programa MSQ ${ }^{\circledR}$ analisador de imagens microestruturais. Para aumentos superiores a 1000X, foi utilizado um microscópio eletrônico de varredura.

O ataque químico utilizado foi com Nital $1 \%$ para visualização no microscópio óptico e Nital $3,0 \%$ para visualização no microscópico eletrônico de varredura.

A determinação da fração volumétrica foi realizada através da aplicação de uma rede de pontos sobre a imagem da microestrutura, e contando-se o número de pontos coincidentes entre a rede e a fase em estudo, segundo recomendações da ASTM E 562 [17].

A quantificação foi realizada na região de grãos colunares do metal de solda; para identificação de microconstituintes, utilizou-se a terminologia recomendada pelo IIW (International Institute of Welding).

Para determinação do tamanho médio dos grãos da ZTA, foi utilizado o método da interseção, com o uso de micrografias obtidas na etapa de microscopia óptica, com aumento de 500X. Nove segmentos de reta verticais igualmente espaçados foram sobrepostos sobre a micrografia determinando assim o comprimento médio de grãos interceptados em cada segmento. Por fim foi retirada a média para os 9 segmentos, obtendo um valor médio de tamanho de grão para cada região da ZTA (grãos grosseiros (GG) e grãos finos (GF)).

A extensão da ZTA foi obtida por um micrômetro acoplado a um microdurômetro digital; foram realizadas 19 medidas em cada amostra, referente a cada processo, com um distanciamento de $1 \mathrm{~mm}$ entre cada medição.

O perfil de microdureza na junta soldada foi realizado na região que intercepta o passe de raiz, assim como numa região que intercepta os passes de enchimento, seguindo o posicionamento do entalhe nos corpos de prova Charpy; a carga utilizada foi de $200 \mathrm{~g}$ com tempo de aplicação de 15 segundos e espaçamento médio entre impressões de $200 \mu \mathrm{m}$.

Para realização dos ensaios Charpy utilizou-se uma máquina de impacto acoplada a um computador para leitura e tratamento de dados. Os ensaios foram realizados à temperatura ambiente, 
utilizando um pêndulo com capacidade de gerar $300 \mathrm{~J}$. O dimensionamento dos corpos de prova foi realizado de acordo com a norma ASTM E23 [18]. Foram usinados 5 corpos de prova com entalhe posicionado tanto na região do passe de raiz, como na região de passe de enchimento da junta soldada. Após o ensaio de impacto, cada corpo de prova fraturado foi seccionado em duas partes, uma para quantificar o percentual de microconstituintes na ponta do entalhe utilizando-se microscopia óptica e outra para analisar o aspecto da região de fratura utilizando-se microscopia eletrônica de varredura.

\section{Resultados e Discussão}

As análises de composição química nos metais de solda foram realizadas por espectroscopia de massa e estão apresentadas nas Tabelas 3, 4 e 5.

Os resultados indicam que o procedimento $\mathrm{R} 2$ apresentou maior percentual de grãos colunares no metal de solda; isto aconteceu provavelmente em função do menor aporte térmico sobre a junta soldada para este procedimento, decorrentes da utilização de uma maior velocidade de soldagem. O procedimento M2 apresentou o menor percentual de grãos colunares, o que pode ser justificado pela maior aporte térmico sobre a junta soldada, decorrente de uma menor velocidade de soldagem, assim como do emprego de temperatura de interpasse. $\mathrm{O}$ procedimento R1 apresentou uma maior quantidade de região de grãos colunares do que o M1 apesar de ser utilizado um aporte térmico semelhante em ambos os casos. Este resultado pode ser atribuído à predominância da maior velocidade de soldagem utilizada para o procedimento R1. Para confirmar esta influência uma analise mais cuidadosa do gradiente de temperatura na junta soldada seria necessária, principalmente no que se refere à soldagem multipasse.

Tabela 3. Composição química dos metais de solda para os procedimentos M1 e M2.

\begin{tabular}{ccccccccccc}
\hline $\mathbf{C}$ & $\mathbf{M n}$ & $\mathbf{S i}$ & $\mathbf{P}$ & $\mathbf{S}$ & $\mathbf{A l}$ & $\mathbf{V}$ & $\mathbf{C r}$ & $\mathbf{M o}$ & $\mathbf{C u}$ & $\mathbf{N i}$ \\
\hline 0,117 & 1,102 & 0,227 & 0,017 & 0,019 & 0,019 & 0,009 & 0,059 & 0,270 & 0,026 & 0,677 \\
\hline
\end{tabular}

Tabela 4. Composição química dos metais de solda para o procedimento R1.

\begin{tabular}{ccccccccccc}
\hline $\mathbf{C}$ & $\mathbf{M n}$ & $\mathbf{S i}$ & $\mathbf{P}$ & $\mathbf{S}$ & $\mathbf{A l}$ & $\mathbf{V}$ & $\mathbf{C r}$ & $\mathbf{M o}$ & $\mathbf{C u}$ & $\mathbf{N i}$ \\
\hline 0,047 & 1,753 & 0,197 & 0,015 & 0,015 & 0,036 & 0,023 & 0,147 & 0,208 & 0,029 & 0,017 \\
\hline
\end{tabular}

Tabela 5. Composição química dos metais de solda para o procedimento R2.

\begin{tabular}{ccccccccccc}
\hline $\mathbf{C}$ & $\mathbf{M n}$ & $\mathbf{S i}$ & $\mathbf{P}$ & $\mathbf{S}$ & $\mathbf{A l}$ & $\mathbf{V}$ & $\mathbf{C r}$ & $\mathbf{M o}$ & $\mathbf{C u}$ & $\mathbf{N i}$ \\
\hline 0,064 & 1,584 & 0,158 & 0,014 & 0,015 & 0,027 & 0,015 & 0,146 & 0,197 & $<0,008$ & 0,046 \\
\hline
\end{tabular}

A Figura 2 ilustra as regiões de grãos colunares nos metais de solda para cada processo de soldagem e a Tabela 6 apresenta os percentuais obtidos em cada caso.

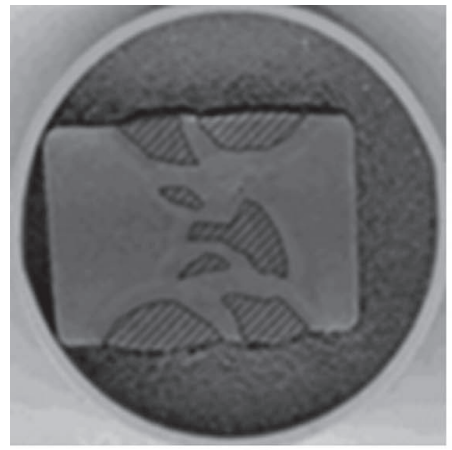

(a)

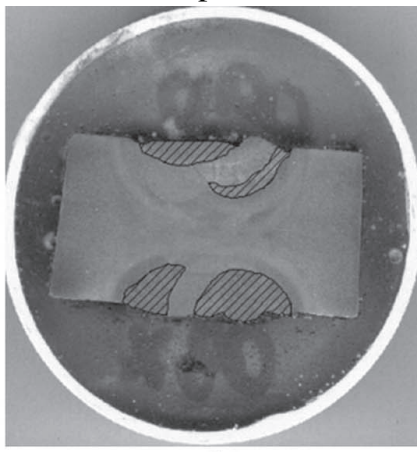

(b)

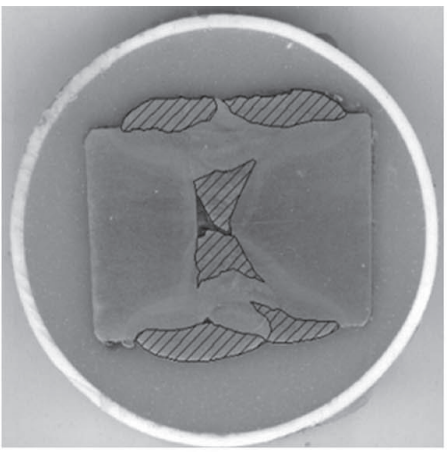

(c)

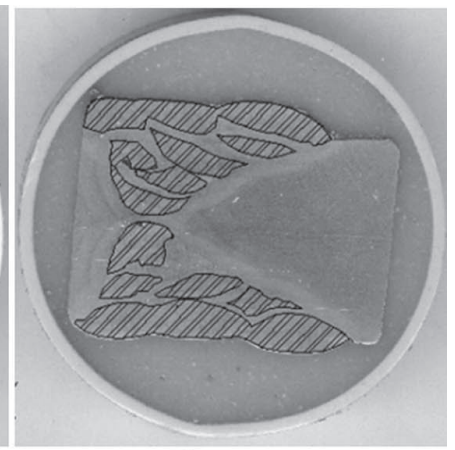

(d)

Figura 2. Regiões de grãos colunares no metal de solda. (a) M1; (b) M2; (c) R1; (d) R2.

Tabela 6. Quantificação de grãos no metal de solda (\%).

\begin{tabular}{c|c|c|c}
\hline \multicolumn{2}{c|}{ PS } & Grãos colunares & Grãos reaquecidos \\
\hline \multirow{2}{*}{ Manual } & M1 & 56 & 44 \\
\cline { 2 - 4 } & M2 & 40 & 60 \\
\hline \multirow{2}{*}{ Robotizado } & R1 & 64 & 36 \\
\cline { 2 - 4 } & R2 & 72 & 28 \\
\hline
\end{tabular}




\section{Extensão da ZTA}

Os resultados de extensão da ZTA para cada procedimento de soldagem estão apresentados na Figura 3; a região tracejada indica os 19 segmentos ao longo da espessura da chapa que foram medidos com o auxílio de um micrômetro.
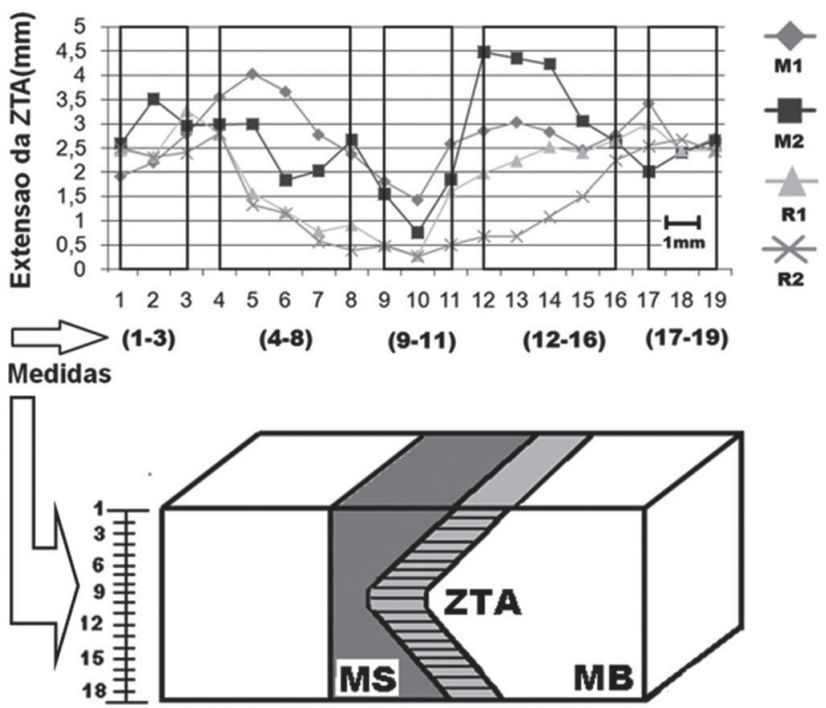

Figura 3. Medidas de extensão da ZTA para cada processo.

Pode-se perceber que a extensão da ZTA variou significativamente em função da sua posição ao longo da seção transversal da chapa, sendo mais considerável para os processos M1 e M2. Este reusltado pode ser atribuído à instabilidade na posição do eletrodo por ser estes processos completamente manuais. Nos procedimentos M1 e M2 os valores da extensão da ZTA variaram de 2,61 a 2,76 $\mu \mathrm{m}$, significativamente maiores do que 1,53 e 1,80 $\mu \mathrm{m}$ obtidos nos processos $\mathrm{R} 1$ e R2. Isto ocorre devido ao maior aporte térmico utilizado, principalmente para o caso do procedimento $\mathrm{M} 2$, onde foi utilizado temperatura de interpasse. O aumento na extensão da ZTA associado com uma maior energia de soldagem, assim como uma maior temperatura de interpasse também foi observado por Monteiro [19] e Thaulow [20] na soldagem de aços microligados de baixo teor de carbono. Na Figura 8, observa-se ainda que nas regiões (1-3) e (17-19) os valores médios de extensão da ZTA dos processos R1 e R2 estão mais uniformes quando comparados com as mesmas regiões para os processos M1 e M2. Este resultado é interessante para obtenção de uma junta soldada com maior repetibilidade, como é esperado em determinadas aplicações, como por exemplo na soldagem de tubulações. Em todos os grupos de medições referentes aos processos R1 e R2, observam-se valores médios de extensão de ZTA bastante semelhantes, apenas para as regiões (12-16) referentes ao processo R2, têm-se uma redução destes valores devido ao menor aporte térmico nos passes de enchimento deste procedimento.

\section{Tamanho de Grão na ZTA}

Os tamanhos dos grãos austeníticos, na região de grãos finos (GF) e de grão grosseiro (GG) da ZTAA, adjacente à região dos passes de raiz para cada corpo de prova, estão indicados na Tabela 7.

Analisando os resultados de tamanhos de grão na região GF, observa-se que não houve variações significativas entre os procedimentos de soldagem. Na região GG entretanto, mais preocupante no que diz respeito às propriedades mecânicas, pode-se observar que os processos M1 e R1 apresentaram os menores tamanhos, $15,43 \mu \mathrm{m}$ e $16,1 \mu \mathrm{m}$ respectivamente, enquanto que os processos M2 e R2 apresentaram os maiores valores $(28,26 \mu \mathrm{m}$ e $20,4 \mu \mathrm{m})$ respectivamente. Estes resultados podem ser justificados pelos maiores valores da energia de soldagem utilizada nas proximidades do passe de raiz. Além disso, o processo M2 utilizou uma maior temperatura de interpasse, contribuindo para o maior aporte térmico observado, favorecendo o maior tamanho de grão encontrado entre todos os processos de soldagem.

Tabela 7. Tamanho de grão nas regiões da ZTA

\begin{tabular}{|c|c|c|c|c|c|}
\hline \multicolumn{2}{|c|}{ PS } & $\begin{array}{c}\text { GG } \\
(\mu \mathrm{m})\end{array}$ & $\begin{array}{c}\text { GG } \\
(\mathrm{ASTM})\end{array}$ & $\begin{array}{c}\text { GF } \\
(\mu \mathrm{m})\end{array}$ & $\begin{array}{c}\text { GF } \\
(\mathrm{ASTM})\end{array}$ \\
\hline \multirow{2}{*}{ Manual } & M1 & 15,43 & 8,7 & 5,90 & 11,5 \\
\cline { 2 - 6 } & M2 & 28,26 & 7,0 & 6,48 & 11,3 \\
\hline \multirow{2}{*}{ Robotizado } & R1 & 16,11 & 8,6 & 5,37 & 11,8 \\
\cline { 2 - 6 } & R2 & 20,43 & 7,9 & 4,70 & 12,2 \\
\hline
\end{tabular}

\section{Análise Microestrutural da ZTAGG}

Para que ocorra boa tenacidade na ZTA é importante observar a quantidade, tipo e distribuição do microconstituinte M-A na ZTA. A presença de microconstituinte M-A pode resultar em zonas de fragilização localizadas, que são regiões com valores de tenacidade baixos e que comprometem a integridade da junta soldada. A formação deste microconstituinte é depende da composição química do material de base e dos ciclos térmicos atuantes durante a soldagem [21-26].

Como a região GG é uma área crítica da junta soldada, procurou-se fazer uma análise qualitativa mais detalhada desta região, mais especificamente na região adjacente ao passe de raiz.

A Figura 4 apresenta as microestruturas das regiões GG obtidas para os quatro procedimentos de soldagem na região adjacente ao passe de raiz.

$\mathrm{Na}$ Figura 4(a) observa-se que para o procedimento M1 ocorreu significativa formação do microconstituinte M-A. Este resultado é provavelmente devido à utilização de um aporte térmico relativamente elevado $(1,25 \mathrm{KJ} / \mathrm{mm})$, o que possibilitou uma taxa de resfriamento menor que o empregado para o procedimento R1. Desta forma ocorreu o favorecimento de uma maior formação de M-A em detrimento a redução da tenacidade nesta região da junta soldada [21-28].

No procedimento M2, o emprego de um aporte térmico superior ao do procedimento M1, da ordem de $1,87 \mathrm{~kJ} / \mathrm{mm}$, assim como a utilização de uma temperatura de interpasse maior, pode ter favorecido a decomposição do microconstituinte M-A, já que ocorre um aumento no tempo de resfriamento (Figura 4(b)). 


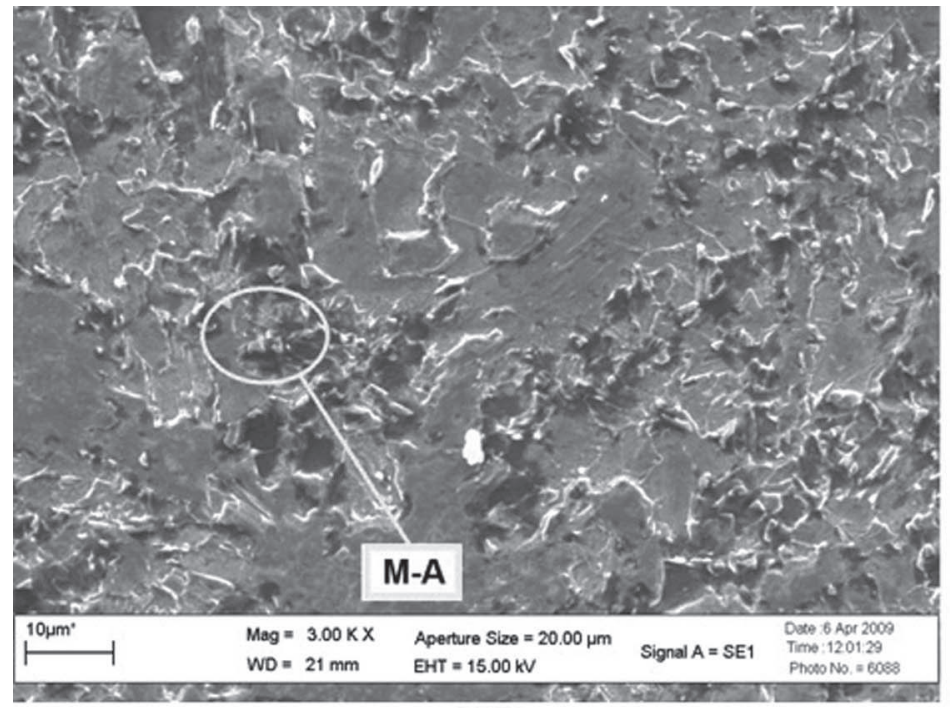

(a)

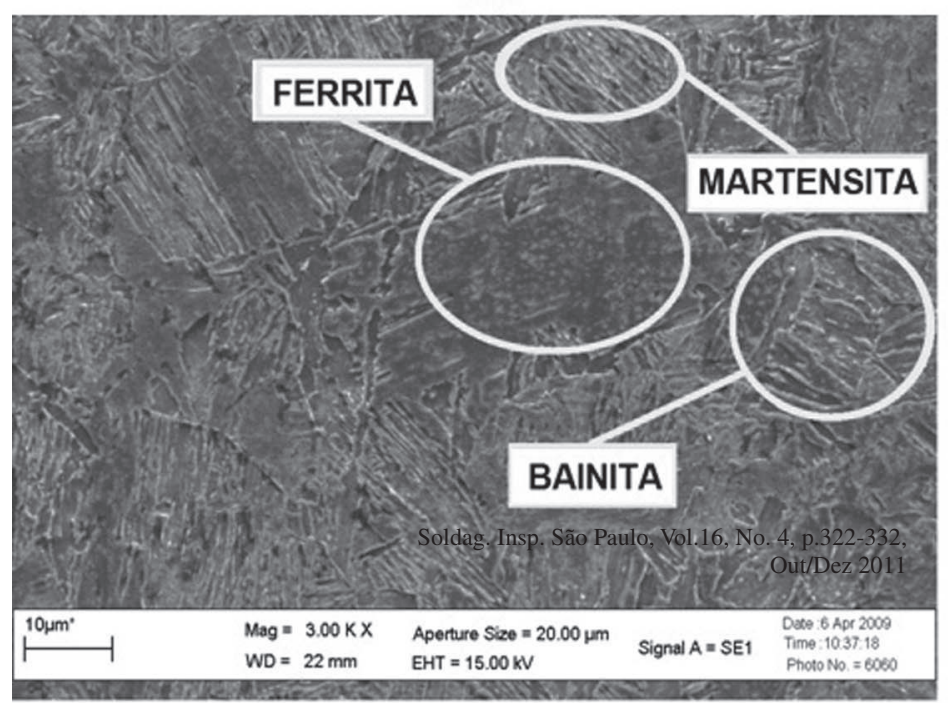

(c)

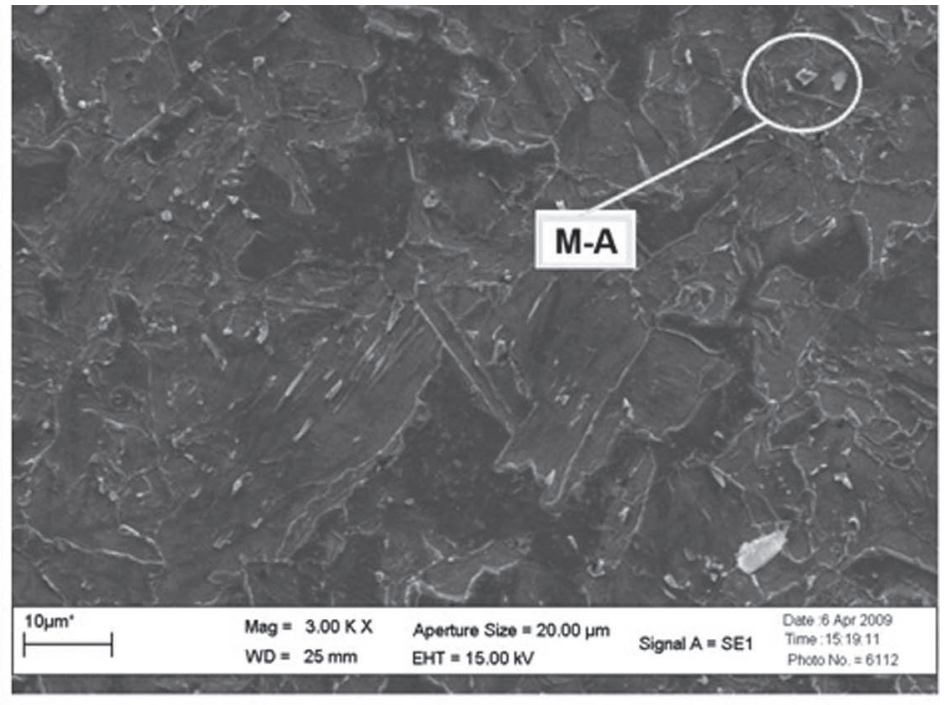

(b)

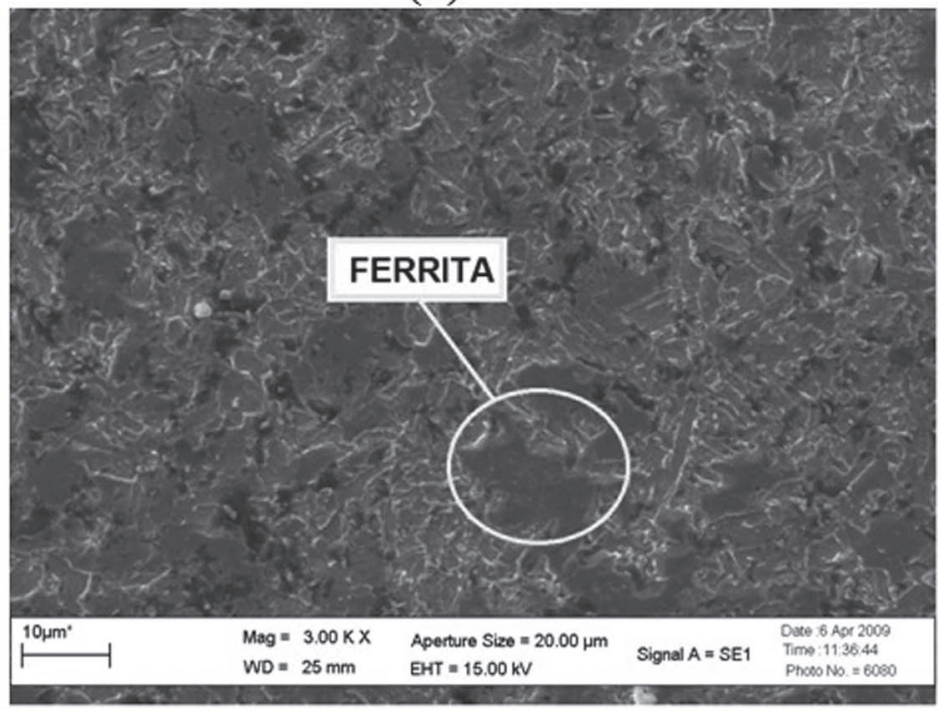

(d)

Figura 4. Microcontituintes presentes nas regiões GG obtidas nos processos M1(a), M2 (b), R1 (c) e R2 (d).

Segundo Matsuda et al [25], ao realizar um estudo sobre a influência do constituinte M-A nas propriedades mecânicas e metalúrgicas de aços ARBL, ocorre um incremento da fração volumetrica de M-A com o aumento no tempo de resfriamento, porém, para tempos de resfriamento muito prolongados pode ocorrer decomposição do M-A em ferrita e carbetos; para o caso do procedimento $\mathrm{M} 2$, isto pode ser comprovado pelos menores valores de microdureza encontrados na região da ZTA; a ferrita tende a reduzir a resistência mecânica da ZTA, já que este microconstituinte, em geral, é macio, dúctil e tenaz, porém, de baixa dureza e resistência mecânica [7].

No procedimento $\mathrm{R} 1$ foi empregado um baixo aporte térmico devido à uma maior velocidade de soldagem. Isto contribuiu para uma maior taxa de refriamento, não verificando a presença de M-A com morfologia semelhante à observada para o procedimento M1. A microestrutura resultante apresentou ferrita, bainita do tipo inferior e martensita (Figura 4(c)). Estes microconstituintes propiciam melhores valores de resistência e tenacidade se comparada com a microestrutura com predominância de ferrita $[7,22]$.

No procedimento $\mathrm{R} 2$, foi utilizado um maior aporte térmico na raiz, soldada com o processo TIG de forma mecanizada, com valor da ordem de $2,1 \mathrm{~kJ} / \mathrm{mm}$, o que possibilitou a formação de uma microestrutura contendo ferrita e agregados eutetóides (Figura 4(d)), onde provavelmente o microconstituinte M-A foi decomposto devido a baixa taxa de resfriamento. M-A foi decomposto devido a baixa taxa de resfriamento. De acordo com as microestruturas observadas para todos os procedimentos de soldagem, aquela formada por ferrita, bainita e martensita, referente ao procedimento $\mathrm{R} 1$, devem apresentar melhores caracterísiticas de propriedades mecânicas, sendo necessário a medição da tenacidade nesta região a fim de comprovar esta análise qualitativa. 


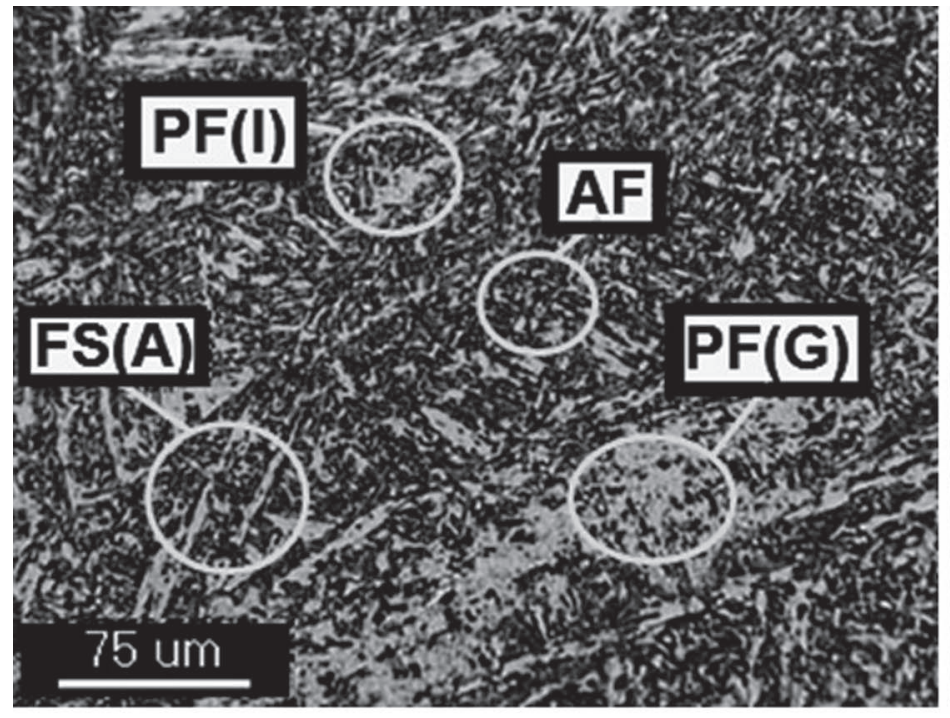

(a)

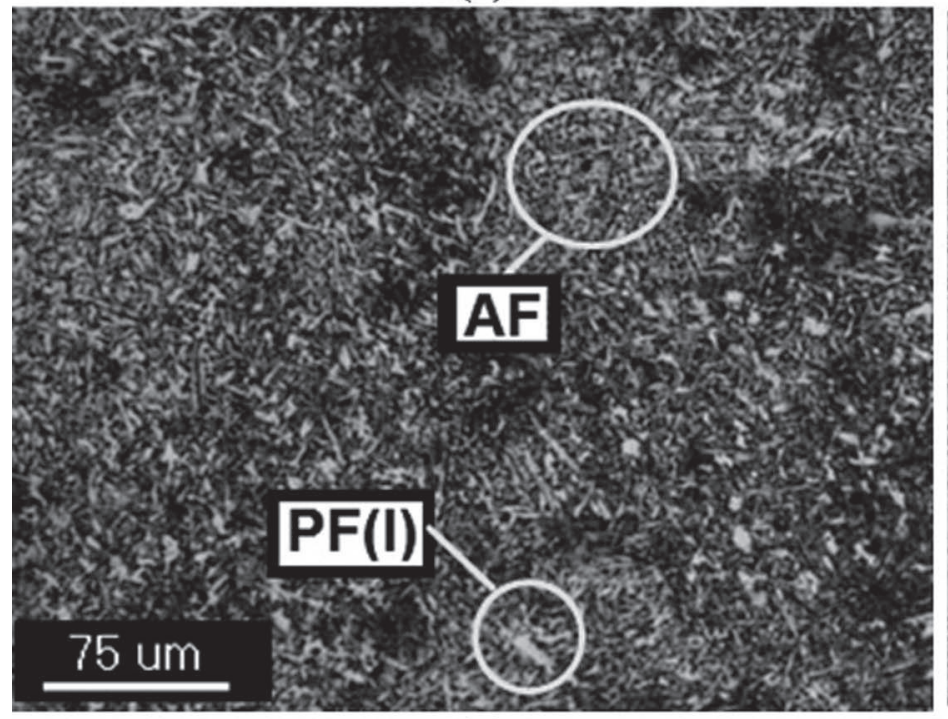

(c)

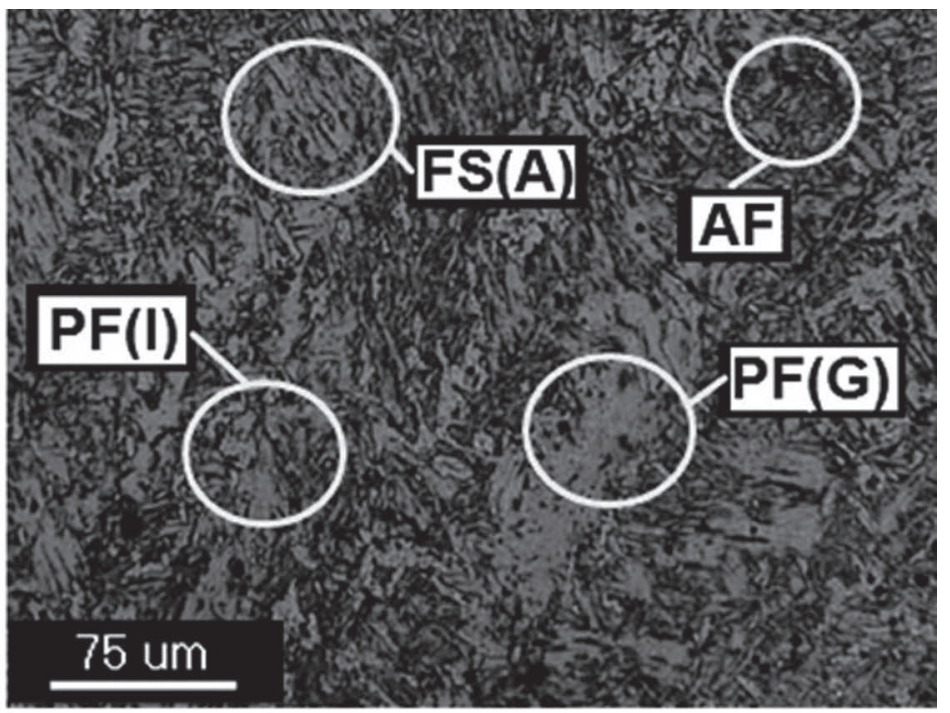

(b)

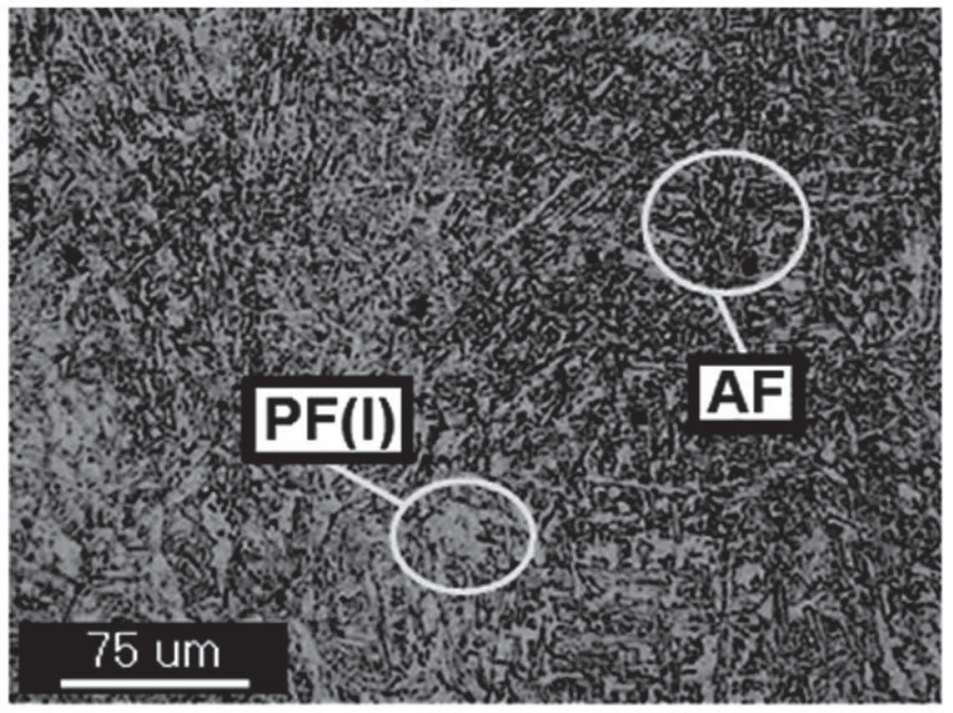

(d)

Figura 5. Microcontituintes presentes nos metais de solda obtidos pelos processos M1(a), M2 (b), R1 (c) e R2 (e).

\section{Quantificação dos Microconstituintes nos Metais de Solda}

A Figura 5 apresenta as microestruturas dos metais de solda obtidos através dos 4 procedimentos e processos de soldagem utilizados e, na Figura 6 tem-se as frações volumétricas dos microconstituintes presentes nos metais de solda obtidos em cada procedimento de soldagem. Pode-se observar que os percentuais de Ferrita Acicular (AF) nos metais de solda obtidos através dos procedimentos de soldagem R1 e R2 foram praticamente o dobro daqueles obtidos pelos procedimentos utilizando processos manuais, (M1 e M2). Este microconstitunte devido à sua morfologia de pequena granulometria e contornos de alto ângulo, associado com uma elevada densidade de discordâncias confere aos metais de solda uma elevada resistência mecânica com boa tenacidade. A sua presença está associada com elevadas taxas de resfriamento e a presença de determinados elementos de liga além do C como Mn, $\mathrm{Cr}$, Si e Al, com destaque principalmente para o $\mathrm{Mn}$ [29-32].

A composição química do metal de solda referente aos procedimentos de soldagem M1 e M2 apresentou um maior percentual de $\mathrm{C}$, contribuindo para maior formação de agregados de ferrita-carbonetos (FC). Os maiores percentuais de $\mathrm{Mn}$ e $\mathrm{Cr}$ nos procedimentos de soldagem R1 e R2, associado com a maior taxa de resfriamento, proporcionada pelas elevadas velocidades de soldagem nos passes de enchimento e acabamento, conduziram a esta maior proporção de Ferrita Acicular.

Podem-se observar também os maiores percentuais de Ferrita Primária (PF), principalmente de Ferrita de Contorno de grão $(\mathrm{PF}(\mathrm{G}))$ nos metais de solda obtidos pelo processo $\mathrm{M} 2 \mathrm{e}$ de Ferrita Secundaria (FS) no processo M2. Estes microconstituintes proporcionam uma baixa resistência à propagação de trincas prejudicando a tenacidade e a resistência mecânica dos metais de solda [33]. 


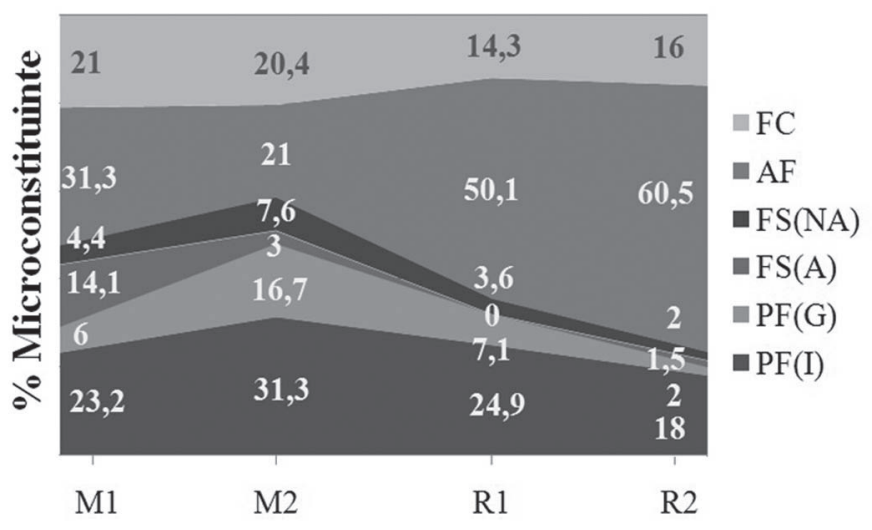

Figura 6. Frações volumétricas de microconstiuintes no metal de solda (\%).

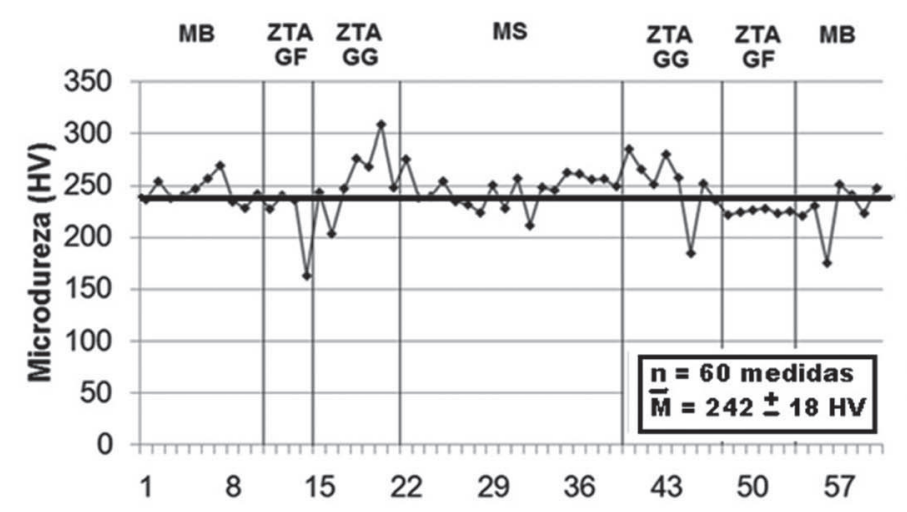

(a)

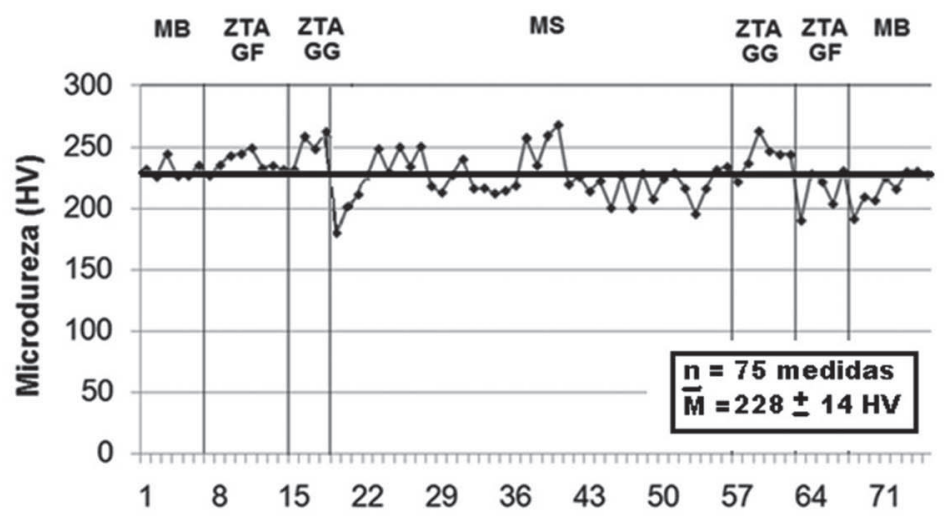

(b)

Figura 7. Perfis de microdureza, procedimento M1 na linha inferior (raiz) (a) e na linha intermediária (b).

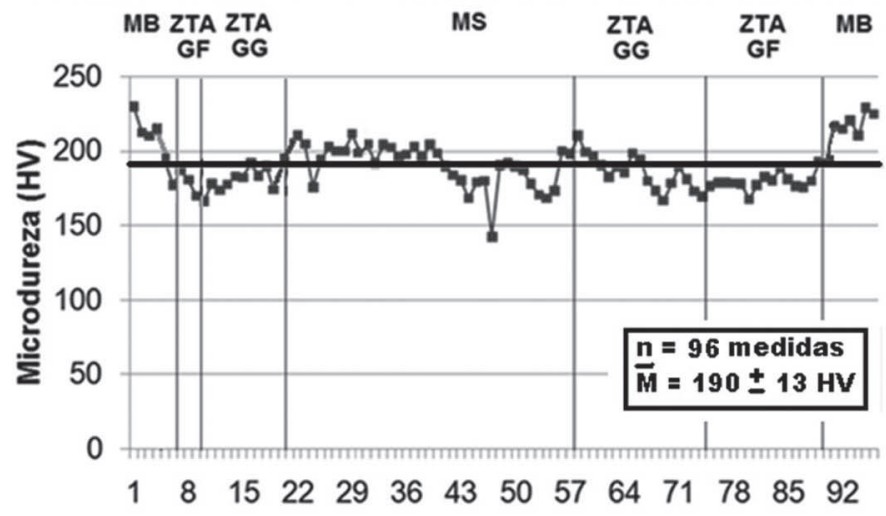

(a)

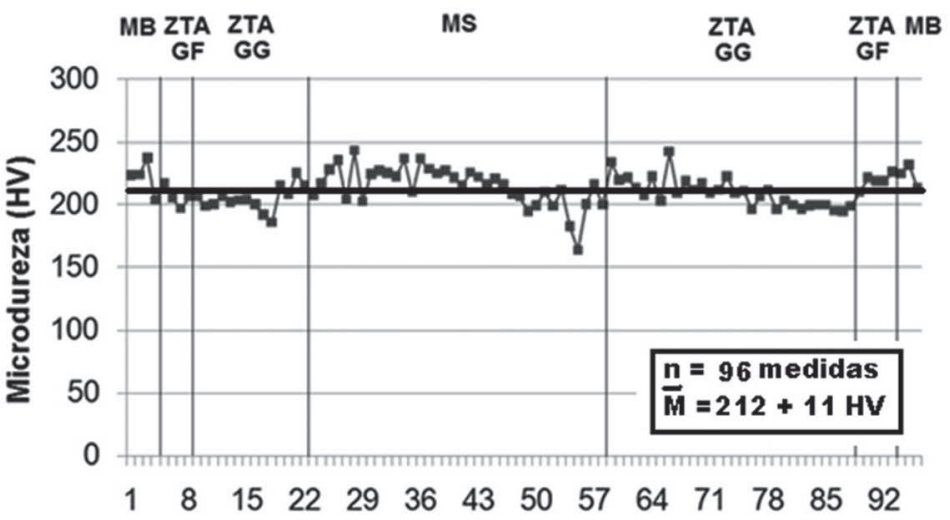

(b)

Figura 8. Perfis de microdureza, procedimento M2 na linha inferior (raiz) (a) e na linha intermediária (b).

\section{Perfis de Microdureza das Juntas Soldadas}

As Figuras 7 e 8 apresentam os perfis de microdureza na linha inferior (na raiz) e na linha intermediária da junta soldada obtida pelo processo M1 e M2, respectivamente.

Os valores médios de microdureza na junta soldada para o procedimento M1 foram de $242 \mathrm{HV}$ na região do passe de raiz e 228 HV na região intermediária, respectivamente. Observase na região da ZTA do passe de raiz a ocorrência de pico de dureza acima de $300 \mathrm{HV}$, certamente decorrente da presença do microconstituinte M-A, conforme foi observado na análise anterior da microestrutura. Como se sabe este é um local mais favorável a iniciação e propagação de trinca, deteriorando a tenacidade nesta região.

No procedimento de soldagem M2, os valores de microdureza apresentaram média de $190 \mathrm{HV}$ na região do passe de raiz e 212 HV na região intermediária, respectivamente. Estes valores são menores que os valores de microdureza 


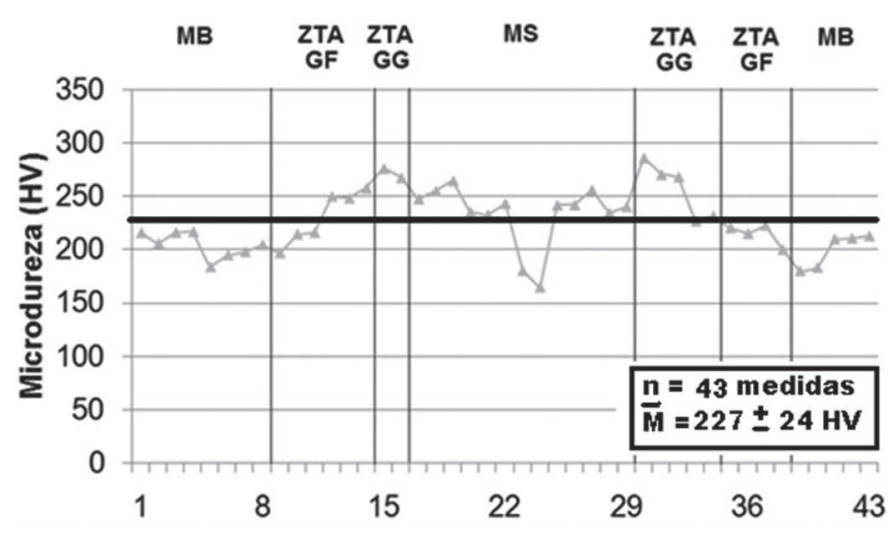

(a)

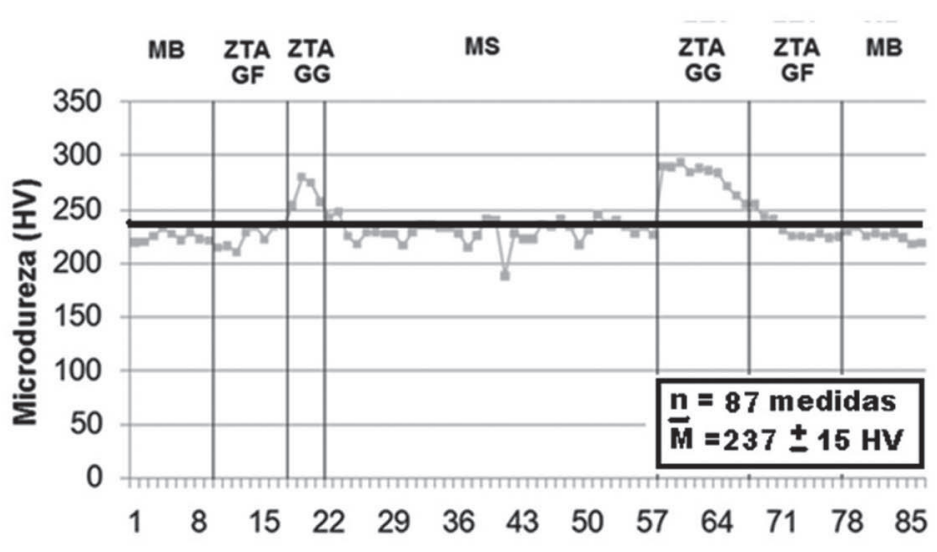

(b)

Figura 9. Perfis de microdureza, procedimento R1 na linha inferior (raiz) (a) e na linha intermediária (b).

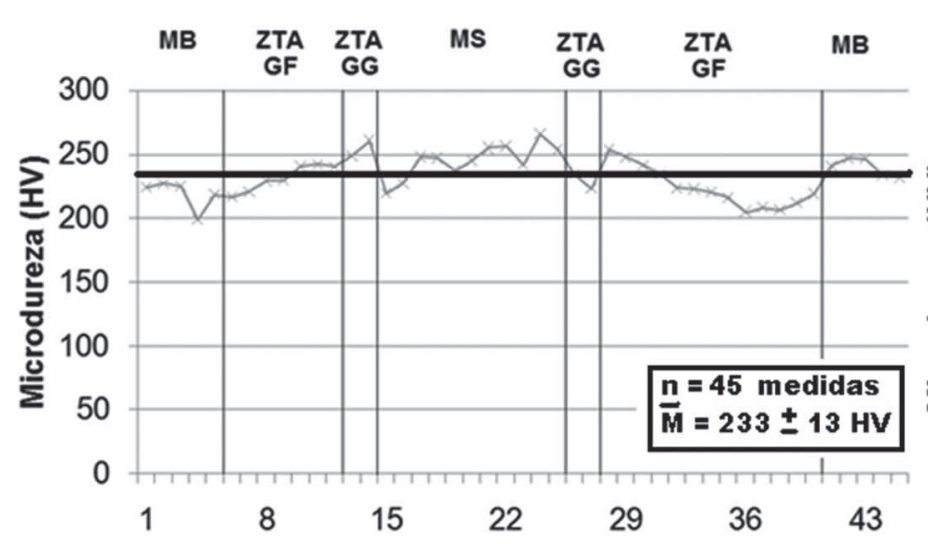

(a)

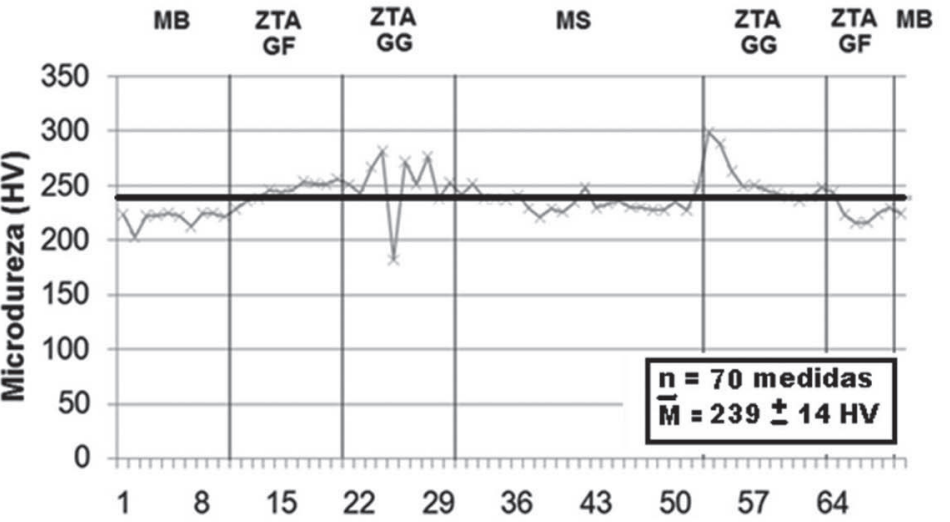

(b)

Figura 10. Perfis de microdureza, procedimento R2 na linha inferior (raiz) (a) e na linha intermediária (b).

encontrados no procedimento M1. Isto mais uma vez é provavelmente consequencia da maior temperatura de interpasse usada, assim como o maior aporte de calor, ocasionando menor taxa de resfriamento e proporcionando e a formação de microconstituintes de menor dureza na junta soldada.

As Figura 9 e 10 apresentam os perfis de microdureza na linha inferior (na raiz) e na linha intermediária da junta soldada obtida pelos procedimentos $\mathrm{R} 1$ e $\mathrm{R} 2$ respectivamente.

No procedimento de soldagem R1, os valores de microdureza apresentaram média de $227 \mathrm{HV}$ na região do passe de raiz e 237 HV na região intermediária, respectivamente. Os elevados valores de dureza na região da ZTA referente a linha intermediária, com valores próximos a $300 \mathrm{HV}$, são provavelmente decorrentes da presença de uma microestrutura com martensita e bainita, influenciada pela maior taxa de resfriamento.

No procedimento de soldagem $\mathrm{R} 2$, os valores de microdureza apresentaram média de $233 \mathrm{HV}$ na região do passe de raiz e 239 HV na região intermediária, respectivamente. Como se vê os valores médios aproxima-se dos valores observados para o procedimento R1.

\section{Análise dos Resultados de Resistência ao Impacto nos Metais de Solda}

Para as análises dos resultados dos ensaios de impacto, considerou-se a energia específica Charpy definida como sendo a energia absorvida (EA) registrada na máquina de ensaio, dividida apenas pela área que fraturou. A fim de comparar os resultados obtidos para todos os processos empregados, já que os corpos de prova Charpy para o processo $\mathrm{R} 2$ romperam parcialmente, a determinação da área fraturada foi realizada a partir da medição direta dos lados fraturados com a utilização de um paquímetro. Para verificar a influência dos percentuais dos diferentes tipos de microconstituintes sobre valores de energia absorvida para cada procedimento de soldagem realizou-se também uma análise microestrutural quantitativa na região onde ocorreu a fratura. Nas Figuras 11 e 12 têm-se os resultados do ensaio de impacto Charpy, assim como o percentual de microconstituintes para cada procedimento de soldagem, tanto para corpos de prova com entalhe posicionado no passe de raiz quanto para corpos de prova com entalhe posicionado nos passes de enchimento do metal solda. 


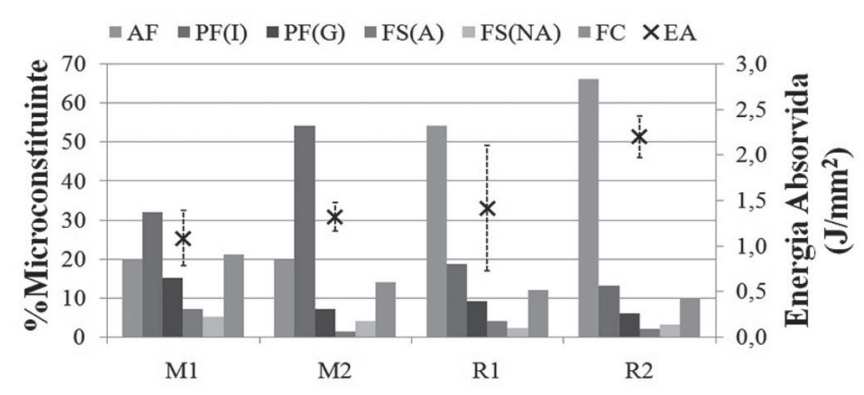

Figura 11. Relação entre os percentuais de AF e os valores de energia absorvida (EA) com o entalhe no passe de raiz.

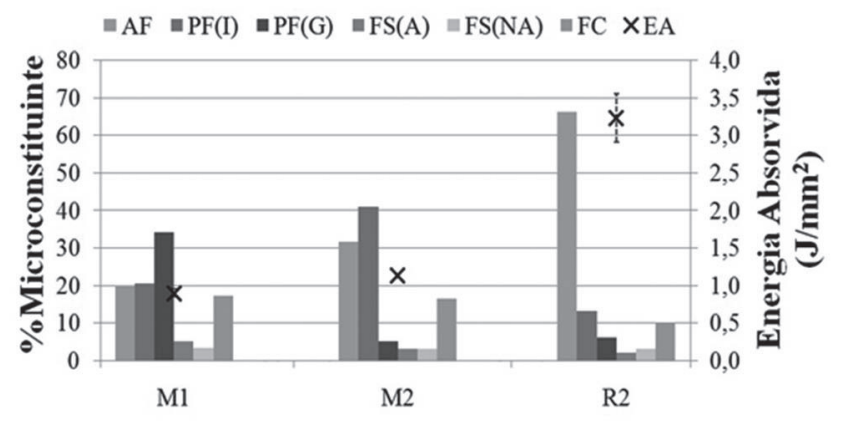

Figura 12. Relação entre os percentuais de AF e os valores de energia absorvida (EA) com o entalhe no passe de enchimento.

Os metais de solda obtidos pelos procedimentos M1 e M2 apresentaram valores baixos de energia absorvida no ensaio de impacto Charpy. Também foram os que apresentaram os menores percentuais da Ferrita Acicular. Para o caso do procedimento M2, o maior valor, em comparação ao procedimento M1, deve-se ao maior percentual de ferrita poligonal decorrente da utilização de temperatura de interpasse, com o refinamento microestrutural pelo passe subseqüente, atuando como tratamento térmico póssoldagem, com ganho de tenacidade.

Os metais de solda obtidos pelos procedimentos R1 e R2 apresentaram maiores valores de energia absorvida no ensaio impacto Charpy, tanto para entalhe no passe de raiz como no passe de enchimento, exceto o para o enchimento do procedimento R1, onde as amostras com entalhe posicionado nesta região foram descartadas devido ao entalhe estar localizado em região com defeito de soldagem, invalidando os corpos de prova Charpy.

Este resultado confirma os benefícios oriundos da maior presença da Ferrita Acicular nestes metais de solda com relação à tenacidade [22,34]; e também a necessidade da escolha adequada dos procedimentos e consumíveis de soldagem a serem utilizados.

\section{Conclusões}

- Um aumento médio de $40 \%$ nas velocidades de soldagem utilizadas nas soldagens robotizadas, proporcionaram uma redução de $38 \%$ na extensão da ZTA apesar do aumento médio de $35 \%$ na corrente de soldagem.
- O aumento de $26 \%$ na energia de soldagem utilizada nos processos SMAW manual, devido à grande redução na velocidade de soldagem, proporcionou um aumento de $16 \%$ no tamanho de grão da região GG e de $18 \%$ na região GF da ZTA.

- A microestrutura na região GG para os procedimentos utilizando processo SMAW manuais, M1 e M2, apresentaram formação de ferrita, bainita, e a presença significativa do microconstituintes M-A dispersos na microestrutura. Nos procedimentos R1 e R2, por outro lado, foi observado formação de bainita e não foi verificado a presença de M-A nas micrografias.

- Os metais de solda obtidos utilizando-se arame AWS E71T$1 \mathrm{C}$ com maior percentual de $\mathrm{Mn}$ e menor percentual de $\mathrm{C}$, e utilizando maior velocidade de soldagem, apresentaram os maiores percentuais de Ferrita Acicular, possibilitando também os maiores valores de energia absorvida no ensaio de impacto Charpy.

\section{Agradecimentos}

Ou autores agradecem à Confab pela doação das chapas de aço, ao CNPq pela bolsa de mestrado e suporte financeiro à pesquisa, à ESAB pela doação dos consumíveis, ao LRSSUFMG pela realização da soldagem e a UAEM-UFCG por oferecer a infra-estrutura necessária para realização da pesquisa.

\section{Referências}

[1] WESSEL, J. K. "Handbook of Advanced Materials" ISBN 0-471-45475-3 Copyright $\square 2004$ John Wiley \& Sons, Inc.

[2] ZHAO, M-C, YANG, K., SHAN, Y., The Effects of ThermoMechanical Control Process on Microstructures and Mechanical Properties of a Commercial Pipeline Steel, Materials Science and Engineering A, v. 335, p. 14-20, 2002.

[3] AMERICAN PETROLEUM INSTITUTE - API 5L, "Specification for Line Pipe. Washington, 42nd ed. January 2000. 153 p.

[4] MEI, P. R.; SILVA, A. L. C. Cap. 2: Decomposição da Austenita e Curvas TTT. Aços e Ligas Especiais, Eletrometal S.A. Metais Especiais, Sumaré - SP, n. 2, p. 47-92, 1988.

[5] ZHANG, Z.; FARRAR, R. A. Influence of $\mathrm{Mn}$ and $\mathrm{Ni}$ on the microestructure and toughness of C-Mn-Ni Weld Metals. Welding Journal, May 1997. 183s-196s.

[6] GRONG, O. Metallurgical modelling of welding. The Institute of Materials - Materials modelling Series. Cambridge, p. 581.1994.

[7] MARQUES, P. V.; MODENESI, P. J.; BRACARENSE, A. Q. Soldagem - Fundamentos e Tecnologia. 1. ed. Belo Horizonte: Editora da UFMG, v. 1, 2005. 363 p.

[8] OHNO, A. Solidificação dos metais; tradutores Paulo da Silva Pontes, Nivaldo Lemos Cupini. São Paulo : Livr. Ciências e Tecnologia, 1988.

[9] MOEINIFAR, S., KOKABI, A.H., MADAAH HOSSEINI H.R. Role of tandem submerged arc welding thermal cycles on properties of the heat affected zone in X80 microalloyed pipe line steel/ Journal of Materials Processing Technology 211 
(2011) 368-375.

[10] MATSUDA, F., IKEUCHI, K., FUKADA, Y., HORII, Y., OKADA, H., SHIWAKU, T., SHIGA, C., SUZUKI, S. Review of Mechanical and Metallurgical Investigations of M-A Constituent in Welded Joint in Japan. Trans. JWRI, Vol. 24 (1995), No.1.

[11] PARANHOS, R. P. R., "Como criar um ambiente de inovação na Pesquisa em tecnologia da soldagem no Brasil?" Soldagem Insp. São Paulo, Vol. 13, No. 2, p. 166-171, Abr/Jun 2008.

[12] ORDOÑEZ, R. E. C. Soldagem e Caracterização das Propriedades Mecânicas de Dutos de Aço API 5L X80 com Diferentes Arames Tubulares, 2004. 130 p. Dissertação (Mestrado) - Faculdade de Engenharia Mecânica, Universidade Estadual de Campinas, Campinas. 2004.

[13] CALOI, G. Análise da Soldabilidade do Aço API 5L X80 Por Meio dos Testes Tekken e de Implante, 2008, 145 p. Dissertação (Mestrado) - Departamento de Ciência dos Materiais e Metalurgia, Pontifícia Universidade Católica do Rio de Janeiro: 2008.

[14] PINTO, P. M. A. S. Soldagem Circunferencial de Tubo API 5L X80 Empregando Processos Manual / Semi-automático, 2006, 113 p. Dissertação (Mestrado) - Departamento de Ciência dos Materiais e Metalurgia, Pontifícia Universidade Católica do Rio de Janeiro: 2006.

[15] RAMIREZ, J. E. Characterization of High-Strength Steel Weld Metals: Chemical Composition, Microestructure, and Nonmetallic Inclusions. Welding Journal, Vol. 87, No 3, p. 6575, Mai/2008.

[16] ROCHA, D. B. Estudo da Soldabilidade do tubo API 5L X80 Utilizando os Processos de Soldagem: MAG com Transferência Controlada e Eletrodo Tubular, 2010, 219 pp. Dissertação (Mestrado) - Departamento de Engenharia Metalúrgica e de Materiais, Escola Politécnica da Universidade de São Paulo: 2010.

[17] ASTM E562. Standard Test Method for Determining Volume Fraction by Systematic Manual Point Count. American Society for Testing and Materials - ASTM E562-08, 2008.

[18] ASTM E23. Standard Test Methods for Notched Bar Impact Testing of Metallic Materials. American Society for Testing and Materials - ASTM E23-02a, 2001.

[19] MONTEIRO, L. S. Estudo de Ciclos Térmicos em Juntas Soldadas de um Aço de Alta Resistência e Baixa Liga Através do Método “in Situ”. Unicamp. São Paulo - SP, p. 89p. 2004. (Dissertação de Mestrado).

[20] THAUlOW, C.; PAAUW, A.; GUTTORMSEN, K. The Heat Affected Zone Toughness of Low Carbon Micro Alloyed Steel. Welding Journal, v. 66, n. 9, p. 266s - 279s, September 1987.

[21] LAITINEN, R. Improvement of Weld HAZ Toughness at Low Heat Input by Controlling the Distribution of M-A Constituents. University of Oulu- Academic Dissertation. Oulu, Finland, p. 204. 2006. (ISBN:951-42-8001-6/ ISSN: 03553213).

[22] BHADESHIA, H. K. D. H.; HONEYCOMBE, R. W. K. Steels - Microstructure and Properties. 3. ed. [S.1.]: Published by Elsevier Ltd., 2006.
[23] VISHNU, P. R. Solid-State Transformation in Weldments. ASM Handbook - Welding, Brazing and Soldering, Metals Park, Ohio, v. 6, p. 70-87, 1984.

[24] LI, Y.; BAKER, T.N. Effect of the morphology of the martensite-austenite phase on fracture of the weld heat affected zone in vanadium and niobium microalloyed steels. Materials Science and Technology, 26 (9). pp. 1029-1040. ISSN 02670836. 2010.

[25] MATSUDA, F., IKEUCHI, K.; FUKADA, Y.; HORII, Y.; OKADA, H.; SHIWAKU, T.; SHIGA, C.; SUZUKI, S. Review of Machanical and Metallurgical Investigations of M-A Constituent in Welded Joint in Japan. Trans. JWRI, Vol. 24, No. 1. Welding Research, 1995.

[26] MATSUDA, F.; IKEUCHI, K.; OKADA, H.; HRIVNAK, I.; PARK, H. Effect of M-A Constituent on Fracture Behavior of 780 and $980 \mathrm{MPa}$ Class HSLA Steels Subjected to Weld HAZ Thermal Cycles. Trans. JWRI, Vol. 23, No. 2. Welding Research, 1994.

[27] KOMIZO, Y.; FUKADA, Y. CTOD Properties and M-A Constituent in the HAZ of C-Mn Microalloyed Steel. Quarterly J. JWS, 6-1 (1988) p.41.

[28] ENDO, S.; SUGA, M.; TSUKAMOTO, H.; MATSUMOTO, K.; ISHIKAWA, H. Effect of Microstructure on HAZ Toughness of Steel Plate for Offshore Structure. Tetsu-to-hagane, 72-12 (1986)s1157.

[29] EVANS, G. M. The Effect of Maganese on the Microestructure and Properties of C-Mn All-Weld Metal Deposits. Welding Journal, March 1980. 67s-75s.

[30] EVANS, G. M. Effect of Chromium on the Microestructure and Properties of CMn All-Weld Metal Deposits. Welding \& Metal Fabrication, August/September 1989. 346-358.

[31] GRONG, O.; MATLOCK, D. K. Microstructural development in mild and lowalloy steel weld metals. International Metals Reviews, 31, n. 1, 1986. 27-48.

[32] JORGE, J. C. F.; SOUZA, L. F. G.; REBELLO, J. M. A. The effect of chromium on the microestructure/toughness relationship of C-Mn Weld Metal deposits. Materials Characterization, Vol. 47, 2001. 195-205.

[33] BUBNOFF, D. V.; VENTRELLA, V. A. Relação entre microestrutura / tenacidade ao impacto do metal de solda do aço API X-70 soldado por eletrodo revestido AWS E8010 - G. Congresso Brasileiro de Ciência dos Materiais - CBECIMAt. Ilha Solteira - SP: [s.n.]. 2002.

[34] EASTERLING, K. Introduction to Physical Metallurgy of Welding. 2. ed. Butterworth-Heinemann: [s.n.], 1992. 